\title{
Experimental investigation of different fluid flow profiles in a rotary multi-bed active magnetic regenerator device
}

Fortkamp, F. P.; Eriksen, D.; Engelbrecht, K.; Bahl, C. R. H.; Lozano, J. A.; Barbose, J. R.

Published in:

International Journal of Refrigeration

Link to article, DOI:

10.1016/j.jirefrig.2018.04.019

Publication date:

2018

Document Version

Peer reviewed version

Link back to DTU Orbit

Citation (APA):

Fortkamp, F. P., Eriksen, D., Engelbrecht, K., Bahl, C. R. H., Lozano, J. A., \& Barbose, J. R. (2018).

Experimental investigation of different fluid flow profiles in a rotary multi-bed active magnetic regenerator device. International Journal of Refrigeration, 91, 46-54. https://doi.org/10.1016/j.ijrefrig.2018.04.019

\section{General rights}

Copyright and moral rights for the publications made accessible in the public portal are retained by the authors and/or other copyright owners and it is a condition of accessing publications that users recognise and abide by the legal requirements associated with these rights.

- Users may download and print one copy of any publication from the public portal for the purpose of private study or research.

- You may not further distribute the material or use it for any profit-making activity or commercial gain

- You may freely distribute the URL identifying the publication in the public portal 


\title{
Experimental investigation of different fluid flow profiles in a rotary multi-bed active magnetic regenerator device
}

\author{
F.P. Fortkamp ${ }^{\mathrm{a}, \mathrm{b}, *}$, D. Eriksen ${ }^{\mathrm{a}}$, K. Engelbrecht ${ }^{\mathrm{a}}$, C.R.H. Bahl ${ }^{\mathrm{a}}$, J.A. Lozano ${ }^{\mathrm{b}}$, \\ J.R. Barbosa Jr. ${ }^{\text {b }}$ \\ ${ }^{a}$ Department of Energy Conversion and Storage, Technical University of Denmark, \\ Frederiksborgvej 399, 4000 Roskilde, Denmark \\ ${ }^{b}$ POLO - Research Laboratories for Emerging Technologies in Cooling and \\ Thermophysics, Department of Mechanical Engineering, Federal University of Santa \\ Catarina, Florianópolis, SC, 88040-900, Brazil
}

\begin{abstract}
A rotary multi-bed active magnetic regenerator (AMR) device was modified to allow testing different fluid flow waveforms, with different blow fractions (i.e. the fraction of the AMR cycle when there is fluid flow in the regenerators). The different values of blow fraction were generated using different cam rings that actuate the poppet valves at the inlet and outlet of the regenerators, controlling how long the valves stay open and the number of valves open at the same time. Results showed that smaller blow fractions yield higher values of temperature span for fixed flow rate and cooling capacity, but lower values of coefficient of performance for the same conditions. An analysis of the shaft and pumping powers showed that shorter blow fractions cause higher pressure drop and higher torque oscillations and mechanical vibrations. The highest value of second-law efficiency of $19.1 \%$ was obtained for the largest blow fraction tested $(80 \%)$. Designs for magnetic refrigerators where the fluid flow waveform can change during operation are also discussed in this paper.
\end{abstract}

Keywords: active magnetic regenerator, magnetic refrigeration, magnetocaloric effect, experimental

\footnotetext{
* Corresponding author at: POLO — Research Laboratories for Emerging Technologies in Cooling and Thermophysics, Department of Mechanical Engineering, Federal University of Santa Catarina, Florianópolis, SC, 88040-900, Brazil

Email address: fabio@polo.ufsc.br (F.P. Fortkamp)
} 


\section{Nomenclature}

\section{Roman}

$B \quad$ Magnetic induction $\quad \mathrm{T}$

c Specific heat $\quad \mathrm{J} \mathrm{kg}^{-1} \mathrm{~K}^{-1}$

$f \quad$ Frequency $\mathrm{Hz}$

L Length m

T Temperature $\quad$ K

Greek

r Torque $\quad \mathrm{Nm}$

$\omega \quad$ Rotational speed $\operatorname{rad~s}^{-1}$

$\Phi \quad$ Utilization factor

$\rho \quad$ Density $\mathrm{kg} / \mathrm{m}^{3}$

$\tau \quad$ AMR cycle period $\quad \mathrm{s}$

Composed and constants

$F_{\mathrm{B}} \quad$ Blow fraction

$\tau_{\mathrm{B}} \quad$ Blow period

S

$\eta_{2^{\text {nd }}} \quad$ Second-law efficiency

$m_{\mathrm{MCM}, \text { total }} \quad$ Total magnetocaloric material mass $\quad \mathrm{kg}$

$\begin{array}{lll}d_{\mathrm{p}} & \text { Particle diameter } & \mathrm{m}\end{array}$

$\dot{W}_{\text {pump }} \quad$ Pumping power $\quad$ W

$\dot{W}_{\text {shaft }} \quad$ Shaft power $\quad$ W

$\Delta P \quad$ Total regenerator pressure drop bar

$\dot{Q}_{\mathrm{C}} \quad$ Cooling capacity $\quad$ W

$\Delta T_{\text {span }} \quad$ Regenerator temperature span $\quad \mathrm{K}$

$\dot{\mathcal{V}}_{\mathrm{f}} \quad$ Volumetric flow rate $\quad \mathrm{L} \mathrm{min}^{-1}$

Subscript

C Cold

Carnot Carnot cycle

Curie Curie point

f $\quad$ Fluid

$\mathrm{H} \quad \mathrm{Hot}$

in Inlet of the regenerator

out Outlet of the regenerator

reg Regenerator 
S Solid

$\begin{array}{ll}\text { Abbreviation } \\ \text { AMR } & \text { Active magnetic regenerator } \\ \text { COP } & \text { Coefficient of performance } \\ \text { Gd } & \text { Gadolinium } \\ \text { MCE } & \text { Magnetocaloric effect } \\ \text { MCM } & \text { Magnetocaloric material } \\ \text { NdFeB } & \text { neodymium-iron-boron magnet } \\ \text { Y } & \text { Yttrium }\end{array}$




\section{Introduction}

Magnetic refrigeration is an emerging cooling technology in which the cooling effect is generated by a solid refrigerant, called the magnetocaloric material (MCM), that undergoes variations in temperature caused by changes in magnetization. In the state-of-the-art implementation of this technology, the so-called active magnetic regenerator (AMR) (Barclay and Steyert, 1982), the magnetocaloric effect (MCE) is enhanced by thermal regeneration. In an AMR, the MCM is distributed in porous beds, and the variations in the applied magnetic field are synchronized with an oscillatory flow of a working fluid that transports energy between the regenerator and external heat exchangers, in a cyclic operation.

Achieving high cooling capacities and large temperature spans at a high thermodynamic efficiency and low cost is still a challenge in the field of magnetic refrigeration at room temperature. In this kind of application, AMR devices usually are compact and make use of permanent magnets as the magnetic field source (Trevizoli et al., 2016), which limits the magnetocaloric effect experienced by the material. The MCE can be enhanced using very large magnetic field variations, which would be possible with superconducting magnets, but this solution requires additional cooling power to be operated and is not cost-effective at low capacities (Bjørk et al., 2016).

In the literature, thermodynamic efficiency can be assessed in terms of the coefficient of performance, COP, which is the ratio of cooling capacity to total input power, but this metric is dependent on the device temperature span. For a fixed cooling capacity, a higher value of power is required to generate higher temperature gradients in the device - for instance, in the case of magnetic refrigeration, a higher amount of magnetic work is needed in order to increase the magnetocaloric effect of the refrigerant - , and hence the coefficient of performance can be very high at low temperature spans, which does not indicate that the device is efficient (only that it is not generating an useful operating point). Another efficiency metric is the second-law efficiency, $\eta_{2^{\text {nd }}}$, the ratio of the coefficient of performance to the maximum ideal value; a high value of $\eta_{2^{\text {nd }}}$ indicates that the device is operating at minimum losses at a certain operating point, making it a more useful metric. In respect to the temperature span, it can be reported as the regenerator temperature span (difference between temperatures of the fluid exiting the regenerators at the hot and cold ends) or as the system temperature span (difference between temperatures of the sources).

Different magnetic refrigerators prototypes can achieve different performances depending on construction characteristics, operating parameters such as frequency and flow rate, magnetocaloric materials used and magnetic circuit design. The AMR device described by Engelbrecht et al. (2012) was able to absorb $400 \mathrm{~W}$ of cooling load (or $142.8 \mathrm{~W} \mathrm{~kg}^{-1}$ relative to MCM mass) over a regenerator temperature span of $10.2 \mathrm{~K}$, but with a COP of 1.46 and second-law efficiency of $5.2 \%$ (according to experimental tests performed by Lozano et al. (2013)). Arnold et al. (2014) presented a compact prototype that achieved a cooling capacity of $50 \mathrm{~W}\left(76.9 \mathrm{~W} \mathrm{~kg}^{-1}\right)$ at a system temperature span of $15 \mathrm{~K}$ (the COP 
was not reported). A larger device proposed by Jacobs et al. (2014) reached a cooling capacity of $2502 \mathrm{~W}\left(1646 \mathrm{~W} \mathrm{~kg}^{-1}\right)$, at a system temperature span of $11 \mathrm{~K}$, a COP of 1.9 and a second-law efficiency of $6.82 \%$; this device shows a specific cooling power much higher than other works described in the present paper due mainly to higher fluid flow rates, a more sophisticated magnetic circuit capable of achieving higher magnetic fields and the use of multi-layered regenerators of first-order magnetocaloric materials (whereas all other works use gadolinium alloys, a second-order material with lower magnetocaloric effect but with better mechanical properties and a wider operating range of temperatures). Aprea et al. (2016) reported the design of a prototype with a cooling power of $55 \mathrm{~W}\left(45.8 \mathrm{~W} \mathrm{~kg}^{-1}\right)$, regenerator temperature span of $6 \mathrm{~K}$ and coefficient of performance of 0.7 (second-law efficiency was not reported, and it is not possible to calculate it because the system temperature span was not reported either); this device was also used in a proof-of-concept of a magnetic air-conditioning system, connecting the hot side to a geothermal probe, and experiments showed a cooling capacity of $100 \mathrm{~W}\left(83.3 \mathrm{~W} \mathrm{~kg}^{-1}\right)$ at a regenerator temperature span of $6 \mathrm{~K}$ with a COP of 0.6 (Aprea et al., 2015). The prototype developed by Lozano et al. (2016) showed a cooling power of $80.4 \mathrm{~W}\left(47.3 \mathrm{~W} \mathrm{~kg}^{-1}\right)$ at a regenerator temperature span of $7.1 \mathrm{~K}$, with $\mathrm{COP}=0.54$ and $\eta_{2^{\text {nd }}}=1.16 \%$. In a work dedicated to investigating different bed geometries in a single-regenerator apparatus, Trevizoli et al. (2017) obtained a coefficient of performance of 1.9 and $\eta_{2^{\text {nd }}}=3.8 \%$ for a cooling power of $7 \mathrm{~W}\left(78.6 \mathrm{~W} \mathrm{~kg}^{-1}\right)$ and a system temperature span of $6 \mathrm{~K}$, using a pin array regenerator. In the study by Eriksen et al. (2016a), the device evaluated in the present work achieved, for an applied cooling load of $81.5 \mathrm{~W}\left(47.9 \mathrm{~W} \mathrm{~kg}^{-1}\right)$, a regenerator temperature span of $15.5 \mathrm{~K}$, a COP of 3.6 and a second-law efficiency of $18 \%$.

Despite the increasing number of reports on the thermodynamic assessment of magnetic refrigeration prototypes, there is still a lack of studies concerning the control aspects of such devices. For instance, in some types of applications (e.g., cooling of perishable substances), temperature stability may be more important than cost or efficiency. In others, rapid cooling (fast temperature pull down) may be desired, thus imposing high cooling capacity requirements during startup. In sum, in any of these cases, not only achieving an operating point (characterized by cooling capacity, temperature span and COP) with a target performance is important, but also controlling the system during transient and steady state operation is also crucial. As an example of a control scheme for a magnetic refrigerator, Aprea et al. (2017) developed a system based on artificial neural networks that could select the best operating parameters (frequency and flow rate) to maximize cooling capacity or the coefficient of performance, based on the sources temperatures.

As it will be seen in the present paper, one mechanism for controlling the performance of AMR devices is through the fluid flow characteristics. Trevizoli et al. (2016) classifies the fluid flow systems of magnetic refrigerators into two kinds. With double displacement pumps or pistons (Arnold et al., 2014; Trevizoli et al., 2017), a single displacer can pump fluid alternatively to up to two regenerators; this configuration allows for a more precise control of the volume 
of fluid displaced in each bed, and hence allows balanced flow periods. Other devices use pump and valving systems (Engelbrecht et al., 2012; Jacobs et al., 2014; Aprea et al., 2016; Lozano et al., 2016), which can operate more complex devices, usually at the cost of high energy consumption (Capovilla et al., 2016) and harder maintenance. The valves used can also be of different kinds, such as electronic, poppet, or rotary valves.

The central argument of this paper is that it is possible to control the cooling capacity, temperature span and coefficient of performance of a multi-bed AMR device by regulating the duration of the blow periods, when the fluid flows through the regenerators. Although studies have been performed for single- and two-bed magnetic refrigerators, multi-bed devices, with more complex flow systems and non-homogeneous magnetic field inside each bed, have not been investigated in terms of the system performance response to the variation of flow periods.

\section{Influence of the blow periods on the performance of an AMR}

The thermodynamic and mechanical cycles of an AMR are established by the periodic time behavior of the applied magnetic field (the magnetic field waveform or profile) and of the fluid displacement through the regenerator beds (the fluid flow waveform). The AMR Brayton cycle is the most common among the AMR devices developed for near room temperature applications. It is composed of four processes: (i) adiabatic magnetization (the MCM is magnetized and warmed up); (ii) isofield cold blow (fluid pumped from the cold end flows through the bed, absorbs heat from the MCM and rejects it to the ambient at the hot heat exchanger); (iii) adiabatic demagnetization (the MCM is demagnetized and cooled down); and (iv) isofield hot blow (fluid pumped from the hot end transfers heat to the MCM and reaches the cold heat exchanger at a temperature lower than that of the cold source).

Among other parameters, the system performance is sensitive to changes in the time span of each of the AMR cycle processess. Thus, changing the synchro-

nization between the magnetic and fluid flow waveforms, in particular controlling the start times and their duration, can result in a performance enhancement. From the ability to independently control the fluid flow and magnetic waveforms, there emerges the important definition of blow fraction, $F_{\mathrm{B}}$, namely the time fraction of the cycle where fluid is displaced through the regenerators (Eriksen, 2016; Nakashima et al., 2017).

The works cited in Section 1 did not study the influence of the blow fraction, which was kept fixed in all experiments. The device characterized by Engelbrecht et al. (2012) and Lozano et al. (2013) used a blow fraction of $66.7 \%$. The prototypes described by Arnold et al. (2014) and by Trevizoli et al. (2017) showed a sinusoidal fluid flow waveform with a continuous flow through the regenerators (although with varying magnitude), being equivalent to a blow fraction of $100 \%$. Jacobs et al. (2014) used $F_{\mathrm{B}}=66.7 \%$ and Aprea et al. (2016) used $F_{\mathrm{B}}=50 \%$. The remainder of this section will review works that studied the effect of this parameter. 
Bjørk and Engelbrecht (2011) numerically studied the performance of an AMR (using the 1D model from Engelbrecht (2008)) with a ramp-like magnetic profile (composed of periods of linear increase or decrease in magnetic field, followed by plateaus of constant magnetization) with different parameters. The flow profile was fixed, consisting of periods of no-flow and plateaus of constant flow rate, although the magnitude of the mass flow rate was varied. The authors considered parallel plates and packed beds of gadolinium spheres with different cross-sections. In their paper, the synchronization was defined as the delay of the initial ramp of the magnetic profile compared to the start of the fluid flow cycle. It was found that a synchronization of $\pm 5 \%$ (i.e. slightly advancing or delaying the magnetic profile in time, in respect to the fluid flow profile) has negligible effect on performance, but larger values of synchronization (positive or negative) can decrease the cooling capacity by 20 to $40 \%$ (in respect to the synchronized profiles). Also, when the duration of the magnetization plateau was changed, an optimal cooling capacity was found when the latter was slightly longer than that of the fluid flow plateau.

Qualitatively, the above observations make a general synchronization rule, that is confirmed by works to be reviewed in the following paragraphs and by the present experimental work: To maximize the cooling capacity, the MCM should be completely magnetized when the cold blow starts, and should remain as such for the entire blow. If the cold fluid starts to flow before the solid matrix reaches its highest temperature, the heat transfer potential is reduced. Likewise, if the magnetic field starts to decrease when there is already some flow, the fluid will not have enough time to absorb the heat. Notice that both the fluid flow and the magnetic waveforms have an effect on this synchronization rule, and hence both can be investigated in detail.

From the point of view of the magnetic profile, the magnetic field change steps should be steep in order to maximize performance (Plaznik et al., 2013). However, accomplishing rapid changes in the magnetic field using rotating permanent magnets is a challenge, usually resulting in increased cost from larger magnets, more complex geometries and higher forces involved. Another strategy for sharp transitions in the magnetic profile was demonstrated by the experiments performed by Benedict et al. (2016), where the nested Halbach cylinders could rotate intermittently and independently of the flow system, composed of a double piston and check valves. Their results demonstrated a larger cooling capacity for cases where the magnetization step was done with no fluid flow (in comparison with cases where the magnets and pistons were moved continuously, generating a sinusoidal magnetic waveform). However, in a commercial scenario, this intermittent motion would generate issues with high noise and large power consumption due to torque oscillations.

A systematic investigation of the influence of the fluid flow waveform was performed with a two-bed device by Teyber et al. (2017). In their study, the magnetic profile was a rectified cosine profile generated by two nested Halbach cylinders. The different fluid waveforms were produced with a double piston and a cam-actuated valve train that diverted fluid from the regenerators, yielding different blow periods. Experiments were performed for a fixed utilization 
(i.e. fixed displaced fluid volume in the regenerators), which result in higher flow rates during shorter blow periods. For the conditions evaluated, blow fractions of around $50 \%$ maximized both the temperature span and the exergetic cooling power, for a given thermal load. According to the authors, the existence of optimal values are due to two balancing effects:

1. If the blow fraction is too large, then the effect described earlier is observed, i.e., the fluid flows while the magnetic field is still changing, decreasing the heat transfer potential

2. If the blow fraction is too low, then the mass flow rate is too high (for a fixed utilization), which reduces the effectiveness of the regenerators

Nakashima et al. (2017) evaluated experimentally the effect of blow fraction in a single-bed AMR device. The blow fraction was varied using different face seals in a rotary valve system that diverted different amounts of fluid from the regenerator, and fluid flow was provided from a gear pump. The magnetic profile was similar to that of Teyber et al. (2017). The cooling capacity was observed to increase with a reduction in the blow fraction (for a fixed utilization). However, due to limitations in the ranges of the parameters tested, the conditions of maximum cooling capacity were not observed. The individual components of the total power were measured (i.e., the power required to rotate the valves, the power to rotate the magnetic circuit and the fluid pumping power). Different face seals resulted in different values of pressure drop in the valve system, with a minimum for the blow fraction of $45 \%$. As a result, a peak in COP was observed for this blow fraction.

\section{Experimental work}

\subsection{Description of the experimental apparatus}

The experimental work described in this paper has been performed with the magnetic refrigeration prototype described in Eriksen et al. (2015b), shown in Fig. 1. The AMR consists of 11 beds of spherical Gd-Y particles, distributed in four layers of different compositions and placed in an annular regenerator between an iron core and a rotating magnet. Each bed has $32.7 \mathrm{~mm}$ of width, $11 \mathrm{~mm}$ of height and $90.2 \mathrm{~mm}$ of length. Table 1 shows the composition, Curie Temperature $T_{\text {Curie }}$, length $L$ and particle diameter $d_{\mathrm{p}}$ of each layer.

\begin{tabular}{c|c|c|c|c}
\hline Layer & Composition & $T_{\text {Curie }}[\mathrm{K}]$ & $L[\mathrm{~mm}]$ & $d_{\mathrm{p}}[\mu \mathrm{m}]$ \\
\hline 1 & $\mathrm{Gd}$ & 291 & 37.1 & $500-600$ \\
2 & $\mathrm{Gd}_{97.5} \mathrm{Y}_{2.5}$ & 287 & 10.5 & $200-500$ \\
3 & $\mathrm{Gd}_{95} \mathrm{Y}_{5}$ & 282.5 & 20.5 & $300-500$ \\
4 & $\mathrm{Gd}_{90} \mathrm{Y}_{10}$ & 272 & 21.5 & $300-500$ \\
\hline
\end{tabular}

Table 1: Composition of the regenerator layers. Layer \#1 is the closest to the hot side. 
The regenerator is positioned vertically, with the cold end at the bottom. An insulated electrical heater generates the thermal load. On the hot end, at the top, two rings of poppet valves, connected to the inlet and outlet of the regenerators and actuated by cams, control the fluid flow between the beds and the hot heat exchanger connected to a chiller. A $4 \%$ vol. solution of ethylene glycol in deionized water acts as the heat transfer fluid. Between the hot heat exchanger and the poppet valves, a set of needle valves are employed to regulate the flow rates through the regenerator, thereby controlling the flow inbalance (Eriksen et al., 2016b). This equalizing procedure was performed only once before all experiments in the present work. Figure 2 shows a schematic flow diagram for the AMR device, although without the flow balancing valves.

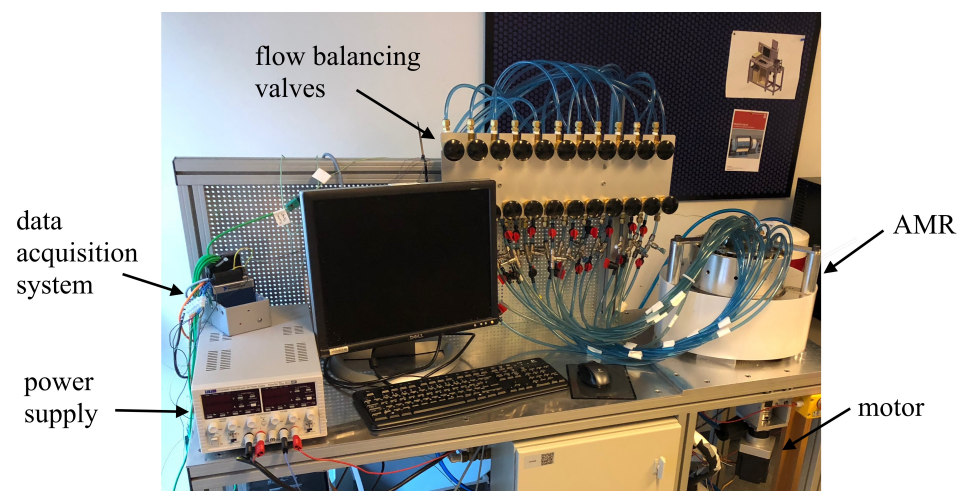

Figure 1: Overall view of the magnetic refrigeration prototype analyzed in this work. Some elemnents of the apparatus are not shown.

The external magnetic circuit consists of a two-pole Halbach cylinder composed of wedges of iron and grade N50 Nd-Fe-B. The magnetic field in the air gap oscillates between 0 and $1.34 \mathrm{~T}$, following the magnetic waveform shown in Fig. 6. The magnet rotates continuously around the regenerator, with its motion controlled by a driving motor and gears.

\subsection{Control of the blow fraction}

As previously mentioned, the focus of this work is to study the effect of different blow fractions (and hence different flow waveforms) on the AMR device. The flow waveform is generated using cams that actuate the poppet valves at the hot end through steel ball rollers, as shown in Fig. 3. The valves are of type MJV-2-MG from Clippard Minimatic. Two identical cam rings are used, for the inlet and outlet valves, although they are out of phase to generate the correct reciprocating behavior. The cam rings are made out of nylon to prevent them from wearing out due to friction with the ball rollers. The cam profiles were designed to yield a ramp fluid flow profile, where the valve is open when the ball roller travel is higher than $0.6 \mathrm{~mm}$ (Eriksen, 2016); the ramp regions occupy only $5 \%$ of the AMR cycle period, and hence the fluid flow waveforms are considered instantaneous in the present work. 


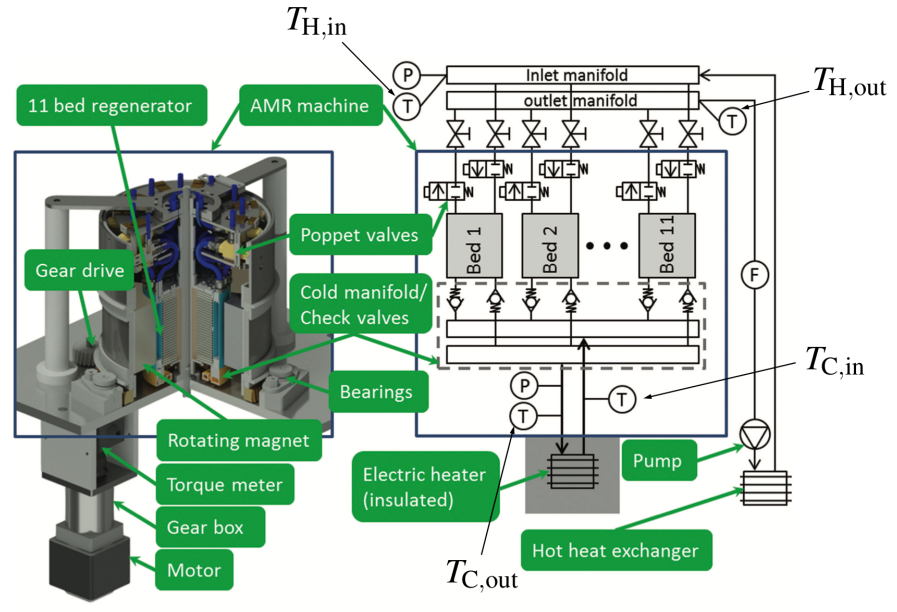

Figure 2: Flow diagram for the AMR device (Eriksen et al., 2016a). The symbol P represent pressure transducers; $\mathrm{T}$, temperature transducers; and $\mathrm{F}$, flow meter. The indicated temperatures of the inlet and outlet of the hot and cold ends are explained in Section 3.3. The flow balancing valves are not represented.

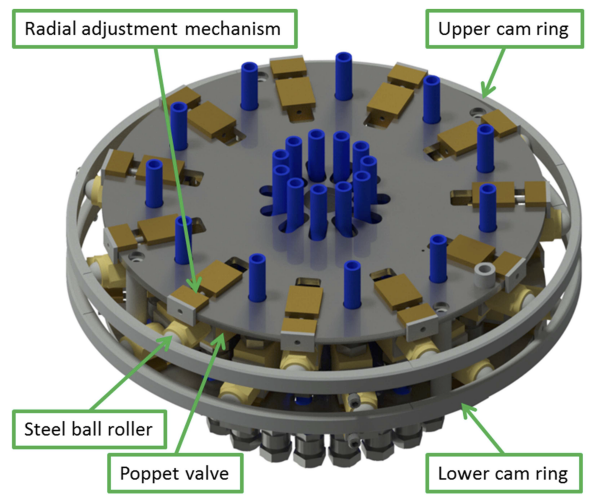

Figure 3: Cams and valve arrays at the top of the regenerator (Eriksen, 2016)

The blow fraction, $F_{\mathrm{B}}$, is defined as:

$$
F_{\mathrm{B}}=\frac{2 \tau_{\mathrm{B}}}{\tau}
$$

where $\tau$ is the AMR cycle period and $\tau_{\mathrm{B}}$ is the individual period for one blow. Because of the flow balacing procedure, one AMR cycle contains two identical blows. In this work, blow fractions of 35, 50 and $80 \%$ were tested. Figure 4 
shows a photograph of two cam rings.

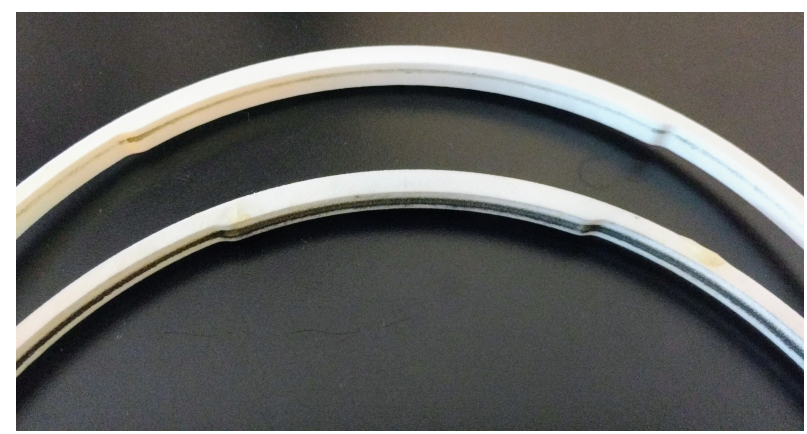

Figure 4: Cams for the blow fractions of 50 and $80 \%$

This rotary multi-bed design represents a fundamental difference between the present work and previous investigations of flow profiles, where the blow fraction was varied by diverting fluid to a by-pass. In the present device, the fluid displaced from the pump is split equally among all regenerators (see Fig. 2), regardless of the blow fraction; the shorter blow fractions will have less valves opened at the same time and for a shorter period, increasing the instantaneous

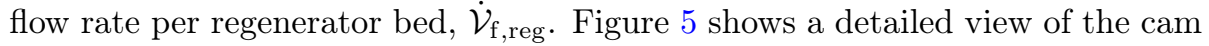
actuating the valves and how the width of the cam affect the number of valves open.

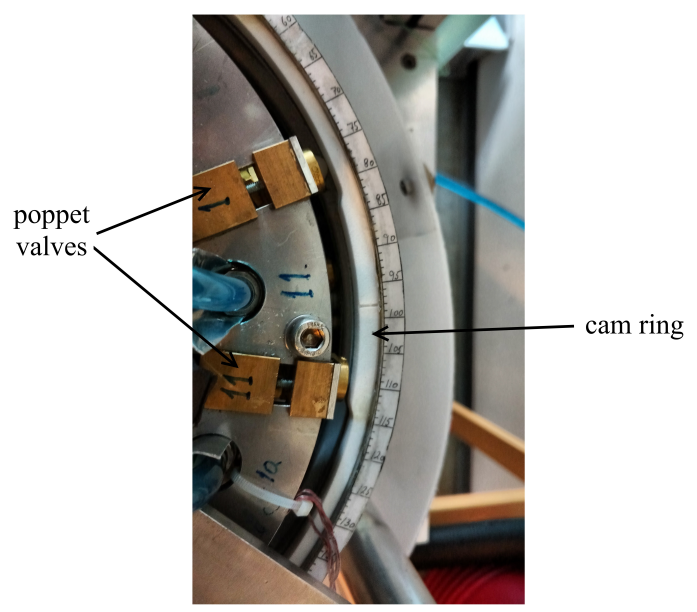

Figure 5: Detail of the cam actuating on the poppet valves

Figure 6 shows a comparison plot between the magnetic profile $B$, measured in the center of the air gap as a function of the angular position (varying between 0 and $180^{\circ}$, covering the one high field region), and the idealized fluid profile $\dot{\mathcal{V}}_{\mathrm{f}, \text { reg }}$ through a given bed for different blow fractions, where it can be seen how 
the the instantanoues flow rate vary with blow fraction, but the displaced mass is constant.

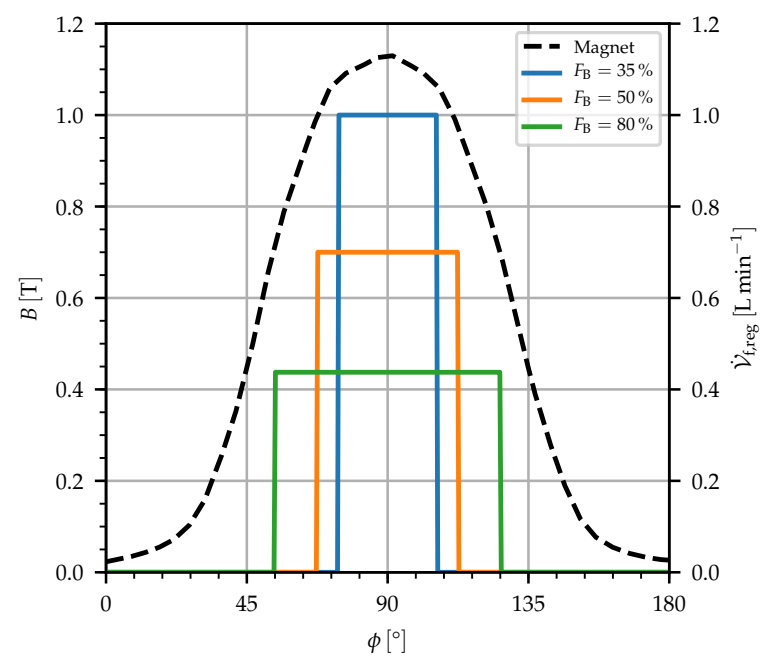

Figure 6: Comparison of the magnetic profile (dashed line) and fluid flow profiles (solid lines, with the indicated blow fractions). The fluid flow profiles indicate the volumetric flow rate through one regenerator bed, $\dot{\mathcal{V}}_{\mathrm{f}, \text { reg }}$, and all profiles have the same displaced mass per blow. The fluid profile for $F_{\mathrm{B}}=35 \%$ has an unitary magnitude as a reference. Only the cold blow is shown.

Each set of experiments of constant blow fraction used a fixed pair of cam rings, which were then removed for the next one to be tested. All tests for a given blow fraction were performed sequentially, with no change in the device structure.

\subsection{Performance metrics}

Unless noted otherwise, all uncertainties described in this section are expressed relative to the full scale of the sensors.

Throughout this paper, the fluid volumetric flow rate, $\dot{\mathcal{V}}_{\mathrm{f}}$, is always reported as the total flow rate provided by the pump, and is measured by a magnetic inductive flow meter (Omega FMG71) at the hot end of the regenerator, with a combined uncertainty of $2 \%$. The pressure drop over the regenerators, $\Delta P$, is calculated as the difference between the measurements of two absolute pressure transducers of type Gems 3100 0-10 bar located at the hot and cold ends, with uncertainty of $0.2 \%$. The pumping power is calculated as:

$$
\dot{W}_{\text {pump }}=\dot{\mathcal{V}}_{\mathrm{f}} \Delta P
$$

with a combined uncertainty of $2 \%$.

A torque transducer (HBM T22/10Nm) is connected to the motor to measure the driving torque $\Gamma$. The rotational speed of the shaft, $\omega$, is measured with an 
optical encoder. Thus, the shaft power delivered by the motor $\dot{W}_{\text {shaft }}$ is given by:

$$
\dot{W}_{\text {shaft }}=\omega \Gamma=\pi f \Gamma
$$

where $f=\omega / \pi$ is the AMR frequency, which is twice the shaft angular frequency, since the magnetic circuit generates two high field regions. The estimated uncertainty of the frequency measurement is $0.5 \%$ of the measured value. The combined uncertainty of the shaft power is $1 \%$.

The temperatures of the fluid at the inlet and outlet of both regenerator ends are measured with type $\mathrm{K}$ thermocouples, with a measurement uncertainty on the order of $0.3 \mathrm{~K}$. However, due to the process of exchanging cams to modify the blow fraction, the combined uncertainty of the temperature span is higher. To replace the cams, it is necessary to remove the regenerator, remove the old cam ring, insert and glue the new ring and then mount the device back again, which requires adjusting the position of the poppet valves to touch the ring. This process is done manually, making it hard to reproduce and temperature span was observed to be highly sensitive to the positioning of the poppet valves. Therefore, the combined uncertainty of the temperature measurement is estimated as $2 \mathrm{~K}$; this value represents the maximum variation in temperature span observed for reproducibility tests with the same conditions and the same cam ring, after careful adjustments of the poppet valves. An estimation of temperature uncertainty based on factors related to the operation of a magnetic refrigerator device was also employed by Lozano et al. (2013).

In this study, the temperature span, $\Delta T_{\text {span }}$, is always reported as the regenerator temperature span:

$$
\Delta T_{\text {span }}=T_{\mathrm{H}, \text { out }}-T_{\mathrm{C}, \text { out }}
$$

where the terms on the right-hand side represent the outlet temperatures at the hot and cold end, respectively.

The cooling capacity $\dot{Q}_{\mathrm{C}}$ is assumed equal to the power applied to the insulated electrical heater, and measured by the data acquisition system with an uncertainty of $0.05 \%$. The coefficient of performance, COP, is defined as:

$$
\mathrm{COP}=\frac{\dot{Q}_{\mathrm{C}}}{\dot{W}_{\text {pump }}+\dot{W}_{\text {shaft }}}
$$

and the second-law efficiency, $\eta_{2^{\text {nd }}}$, as:

$$
\eta_{2^{\text {nd }}}=\frac{\mathrm{COP}}{\mathrm{COP}_{\text {Carnot }}}
$$

where the Carnot coefficient of performance, $\mathrm{COP}_{\text {Carnot }}$, is evaluated in terms of the inlet temperatures at the cold and hot end of the regenerator, respectively 
$T_{\mathrm{C}, \text { in }}$ and $T_{\mathrm{H}, \text { in }}$, as these temperatures are more representative of the reservoir temperatures (Eriksen et al., 2016a):

$$
\mathrm{COP}_{\text {Carnot }}=\frac{T_{\mathrm{C}, \text { in }}}{T_{\mathrm{H}, \text { in }}-T_{\mathrm{C}, \text { in }}}
$$

The experimental data were acquired using a National Instruments system (cDAQ-971), with temperature being measured with a NI 9213 card and current measurements for other transducers with a NI 9203 card mounted in that chassis. The data acquisition system also controls the power delivered from a power supply to the electrical heater and to the motor.

In this paper, all variables are measured in steady-state condition, taking the average of the signals for the last 5 minutes of the experiment.

\subsection{Experimental conditions}

In all tests, the AMR cycle frequency was set at $f=1 \mathrm{~Hz}$ and the outlet hot temperature was set to $T_{\mathrm{H} \text {,out }}=292 \mathrm{~K}$ (by setting the chiller temperature to a few degrees below). Different tests were performed with different flow rates (by adjusting the outlet pressure from the pump and a by-pass valve at the hot end), cooling loads and blow fractions.

As previously explained, because the total displaced mass does not change with the blow fraction, the utilization is also independent, being calculated as:

$$
\Phi=\frac{\rho_{\mathrm{f}} c_{\mathrm{f}} \dot{\mathcal{V}}_{\mathrm{f}}}{2 f m_{\mathrm{MCM}, \text { total }} c_{\mathrm{s}}}
$$

where the specific heat of the solid is set to $c_{\mathrm{s}}=300 \mathrm{~J} \mathrm{~kg}^{-1} \mathrm{~K}^{-1}$ and for the fluid $c_{\mathrm{f}}=4200 \mathrm{~J} \mathrm{~kg}^{-1} \mathrm{~K}^{-1}$; the fluid density is assumed as $\rho_{\mathrm{f}}=1000 \mathrm{~kg} / \mathrm{m}^{3}$ and the total magnetocaloric mass is $m_{\mathrm{MCM}, \text { total }}=1.7 \mathrm{~kg}$.

\section{Results and discussions}

Figure 7 shows the regenerator temperature span as a function of the volumetric flow rate, cooling power and blow fraction. Because of the larger regenerator pressure drop, it was not possible to test the blow fraction of $35 \%$ at higher volumetric flow rates. Notice that, for the range of values of $\dot{\mathcal{V}}_{\mathrm{f}}$ shown in Fig. 7 , the temperature span always increases with the volumetric flow rate, keeping the other parameters fixed. On the other hand, the temperature span decreases with blow fraction. The regenerator effectiveness decrease reported by Teyber et al. (2017) was not seen here due to low values of utilization. Especially for higher flow rates, changing the blow fraction can bring the curves together for different cooling loads; at $3.0 \mathrm{~L} \mathrm{~min}^{-1}$, for instance, it is possible to achieve the same $12 \mathrm{~K}$ of span with cooling loads of 80 and $110 \mathrm{~W}$, just by changing the blow

fraction. However, the somewhat large temperature measurement uncertainty related to changing the cam rings must be kept in mind when analyzing these results. 


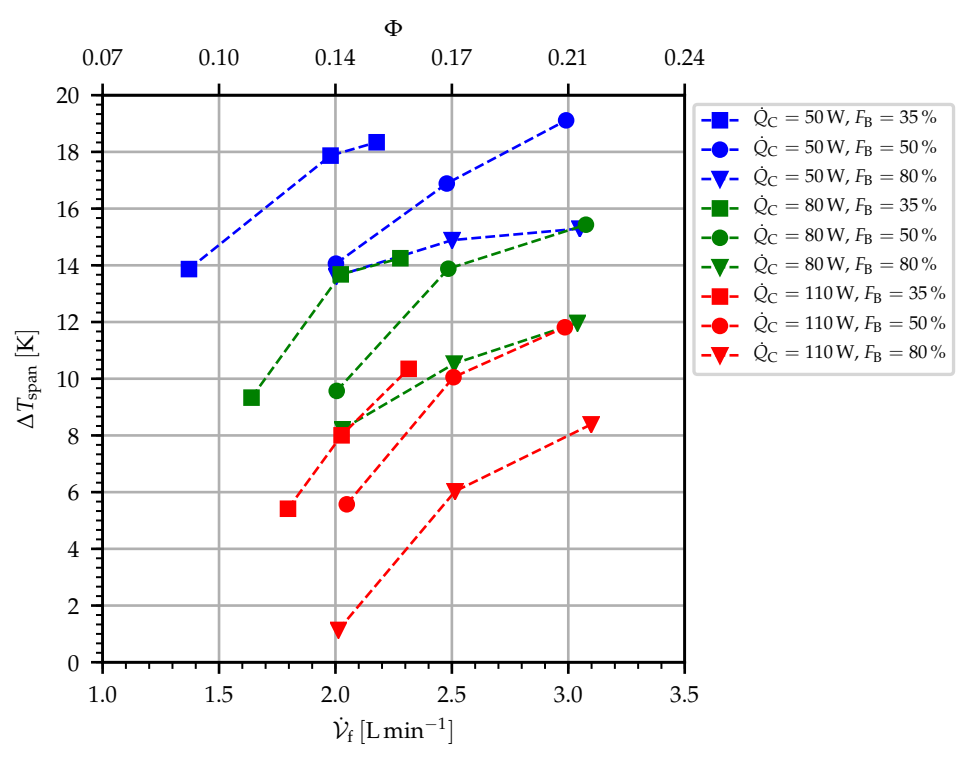

Figure 7: Temperature span as a function of volumetric flow rate for the cooling loads and blow fractions tested

The tempeature span behavior, presented in Fig. 7, can be explained with the help of Fig. 6. One can see why the temperature span for a given cooling capacity decreases with the blow fraction; the larger flow periods result in the phenomenon which all works cited in Section 2 showed as detrimental to performance: the simultaneous fluid flow and magnetization. For the flow profile for $F_{\mathrm{B}}=35 \%$, the fluid begins to flow when the magnetic field is close to its maximum (and consequently when the solid refrigerated is close to its maximum temperature), resulting in higher heat transfer rates.

Results for the coefficient of performance are presented in Fig. 8, where the trends oppose those for the temperature span. The coefficient of performance decreases with flow rate, and increases with cooling capacity and blow fraction. However, it should be noted that the temperature span (shown in Fig. 7) decreased with increasing cooling capacity. To better explain the behaviour of the COP, a breakdown of the power components is shown in Figs. 9 and 10 for the pumping and shaft power, respectively. Notice how the pumping power variation with cooling capacity is negligible, and that this component of power decreases with higher blow fractions, since for constant utilization larger flow periods result in lower fluid velocities and hence lower pressure drop (Plaznik et al., 2013). Shaft power dominates the energy consumption for this device, mostly because of torque oscillations and mechanical inefficiencies in the drive system (gears, bearings etc.). Both components of power decrease with blow fraction - pumping power due to the pressure drop, and shaft power because of mechanical vibrations (noticeably larger when the cam ring with lower blow 
period is used). These mechanical oscillations and the uncertainties in torque and frequency measurements are the likely cause for the non-monotonic change of the shaft power in Fig. 10 for the blow fraction of $80 \%$ and cooling capacities of 50 and $80 \mathrm{~W}$.



Figure 8: Coefficient of performance as a function of the volumetric flow rate for the cooling loads and blow fractions tested

When comparing Figs. 7 and 8, it is interesting to notice how some sets of points have approximately the same cooling capacity and temperature span, but different values of coefficient of performance. To make the dependence of the flow profile on COP more explicit, Fig. 11 shows this relationship for target conditions; all points on the same curve have the same cooling capacity and temperature span for different $F_{\mathrm{B}}$. Here, different blow fractions require different values of volumetric flow rate, resulting in different values of shaft and pumping power. The analysis of Fig. 11 shows opposite trends for the two depicted curves because of the combined effects of blow fraction on vibration, volumetric flow rate and pressure drop. For instance, although a smaller blow fraction might require lower flow rates to achieve the target temperature span, the pressure drop increase due to the lower blow fraction is such that pumping power may either increase or decrease. Therefore, it is possible to control the performance of the magnetic refrigerator with a proper selection of the fluid flow profile to attain higher values of COP for a given operating point. This can be done with no changes in the magnetic circuit or the regenerator, and Section 5 will present ideas for the dynamic change of blow fraction.

The behavior of the second-law efficiency as a function of volumetric flow rate, cooling capacity and blow fraction is shown in Fig. 12. The highest 


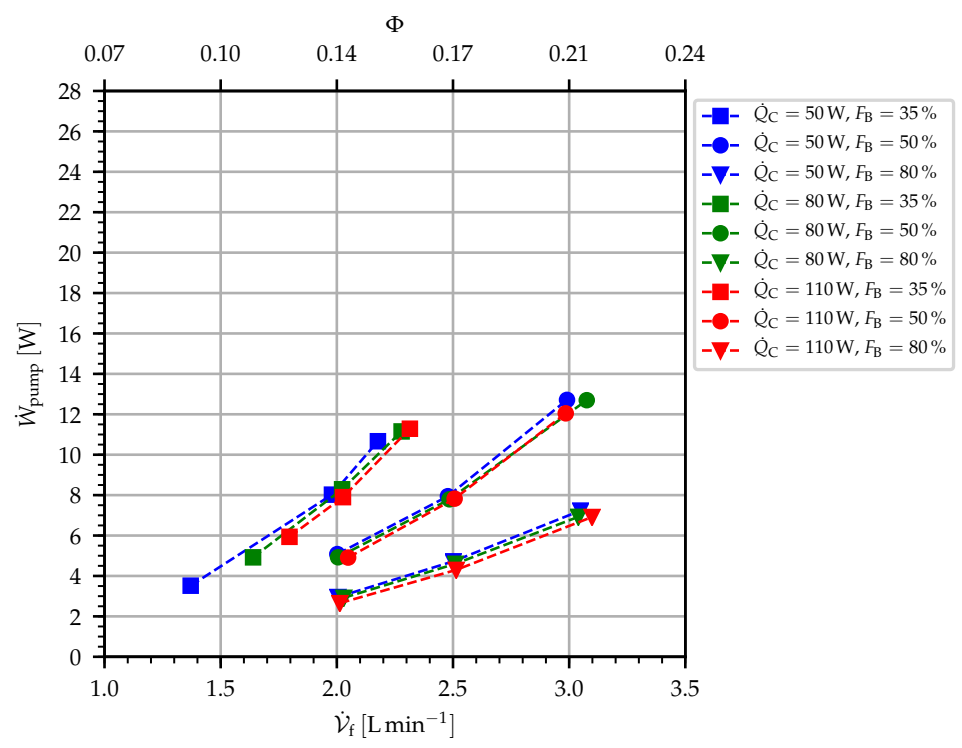

Figure 9: Pumping power as a function of the volumetric flow rate for the cooling loads and blow fractions tested



Figure 10: Shaft power required to rotate the regenerators as a function of the volumetric flow rate for the cooling loads and blow fractions tested 


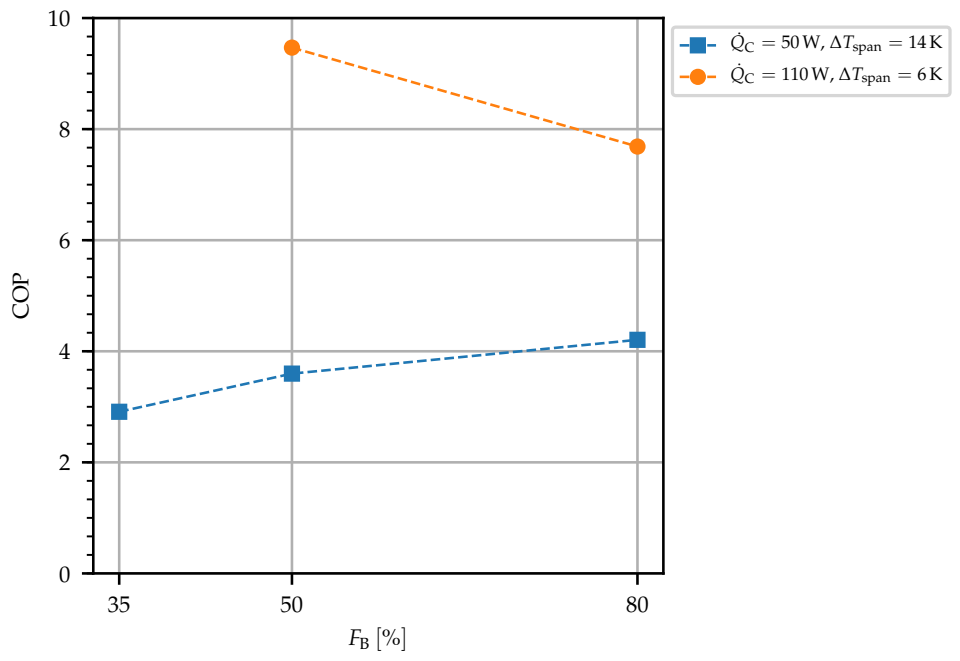

Figure 11: Coefficient of performance as a function of blow fraction for the indicated target conditions

second-law efficiency of $19.1 \%$ is achieved for $\dot{Q}_{\mathrm{C}}=80 \mathrm{~W}, \Delta T_{\text {span }}=10.5 \mathrm{~K}$ and $\mathrm{COP}=6.1$; for comparison, the highest value of second-law efficiency previously achieved with the present device was $18 \%$ for an operating point of $\dot{Q}_{\mathrm{C}}=81.5 \mathrm{~W}, \Delta T_{\text {span }}=15.5 \mathrm{~K}$ and $\mathrm{COP}=3.6$, using a blow fraction of $50 \%$ and a smaller frequency of $0.61 \mathrm{~Hz}$ (Eriksen et al., 2016a). This shows the potential for higher thermodynamic efficiency when using longer blow periods. For the maximum temperature span of $19.1 \mathrm{~K}$ at a cooling power of $50 \mathrm{~W}$, the device achieved a COP of 1.6 and a second-law efficiency of $10.4 \%$. In general, using the smallest tested blow fraction of $F_{\mathrm{B}}=35 \%$ resulted in the lowest values of second-law efficiency of the data set (below 13\%) due to higher values of power consumption for shorter blows (see Figs. 10 and 9). The exception is the negative value of $\eta_{2^{\text {nd }}}$ shown in Fig. 12 for $F_{\mathrm{B}}=80 \%$, explained by the corresponding low value of regenerator temperature span shown in Fig. 7; when including the temperature difference across the hot heat exchanger, the system temperature span (between the hot and cold sources) is negative, which results in a negative Carnot COP according to Eq. (7). At this operating point, the device is no longer functioning as a refrigerator.

\section{Novel designs for a varying flow profile device}

It was shown in Section 4 how different blow periods are suitable for different performance metrics. Shorter blows generally result in higher temperature span for a given cooling load, while longer blows result in higher COP, provided that the machine can achieve the required temperature span. As mentioned in 


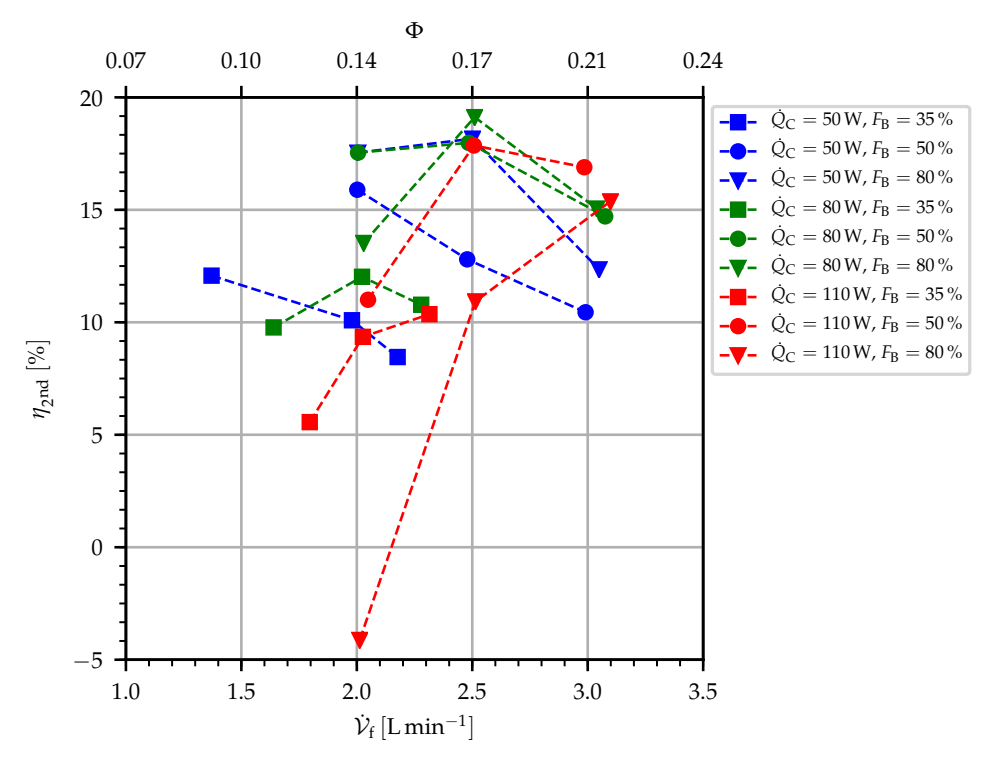

Figure 12: Second-law efficiency as a function of volumetric flow rate for the cooling loads and blow fractions tested

Section 1, the same refrigerator might have to operate under different conditions, and hence the question of varying flow profiles during operation rises.

Due to practical limitations with the AMR device studied in this work, the flow profiles were studied with cam rings that were attached to the structure; and changing the profile required disassembling the prototype, replacing the ring, and then mounting the regenerator back again. A novel design for this kind of multi-bed rotary active magnetic regenerator, which would allow for dynamic changes in blow fractions, involves the use of multiple cam rings in a strucutre that would be co-axial with the regenerator, and this structure could slide until the desired ring were in touch with the regenerator valves, as proposed by Eriksen et al. (2015a). Figure 13 shows an schematic diagram of how two rings could actuate on the same set of valves.

Another way of generating variable flow profiles is with the use of electronic valves, in which the opening and closing times can be controlled. Cardoso et al. (2016) proposed and modelled a digital hydraulic system for a magnetic refrigerator, and this solution was implemented and successfully tested in an AMR device (Dutra et al., 2017). The control logic for this implementation was described by Hoffmann et al. (2017). However, the high electrical power consumption and cost of electronic valves still remains as a challenge, in particular for low-capacity systems, where the cooling capacity could be consumed by the parasitic thermal load of the electrical actuators of the valves. 


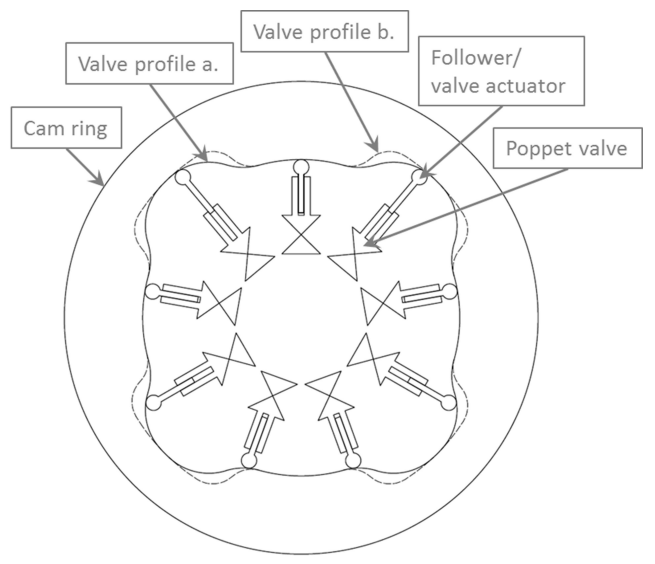

Figure 13: Schematics of multiple cam rings actuating on the valves (Eriksen et al., 2015a; Eriksen, 2016)

\section{Conclusions}

A rotary multi-bed AMR device was modified to allow investigating the effect of different flow profiles on its performance. The primary motivation is to be able to control the performance metrics during operation by changing the blow fraction, which is the main variable studied in this work and which corresponds to the period in the cycle when the regenerators are experiencing fluid flow. It was found that the temperature span was higher for lower blow periods, mainly because of higher average magnetic field during the cold blow. However, reducing the blow fraction resulted in higher pressure drop and higher torque; as a consequence, the coefficient of performance decreased when the blow fraction was reduced. It was shown that, for the same target conditions of cooling capacity and temperature span, it was possible to achieve different values of COP by changing the blow fraction. In addition, the maximum second-law efficiency obtained in this work $(19.1 \%)$ was attained for the highest value of blow period tested $(80 \%)$, for a cooling capacity of $80 \mathrm{~W}$, regenerator temperature span of $10.5 \mathrm{~K}$ and COP of 6.1. Novel designs for dynamically changing the fluid flow profile during operation of a magnetic refrigerator were also discussed.

\section{Acknowledgments}

F.P. Fortkamp wishes to acknowledge the financial support of Capes, through the PDSE program (Process no. 88881.134614/2016-01), for supporting his external stay at the Technical University of Denmark. This work was in part financed by the ENOVHEAT project which is funded by Innovation Fund Denmark (Contract no 12-132673). Financial support from CNPq (Grant no. 443696/20144), Embraco and the EMBRAPII Unit Polo/UFSC is also duly acknowledged. 


\section{References}

Aprea, C., Greco, A., Maiorino, A., 2015. GeoThermag: a geothermal magnetic refrigerator. International Journal of Refrigeration 59, 75-83.

Aprea, C., Greco, A., Maiorino, A., 2017. An application of the artificial neural network to optimise the energy performances of a magnetic refrigerator. International Journal of Refrigeration 82, 238-251.

Aprea, C., Greco, A., Maiorino, A., Masseli, C., 2016. The energy performances of a rotary permanent magnet magnetic refrigerator. International Journal of Refrigeration 61, 1-11.

Arnold, D. A., Tura, A., Ruebsaat-Trott, A., Rowe, A., 2014. Design improvements of a permanent magnet active magnetic refrigerator. International Journal of Refrigeration 37, 99-105.

Barclay, J. A., Steyert, W. A., June 1982. Active Magnetic Regenerator. United States Patent no. 4332135.

Benedict, M. A., Sherif, S. A., Beers, D. G., Schroeder, M. G., 2016. Design and performance of a novel magnetocaloric heat pump. Science and Technology for the Built Environment 22 (5), 520-526.

Bjørk, R., Engelbrecht, K., 2011. The influence of the magnetic field on the performance of an active magnetic regenerator (AMR). International Journal of Refrigeration 34, 192-203.

Bjørk, R., Nielsen, K. K., Bahl, C. R. H., Smith, A., Wulff, A. C., 2016. Comparing superconducting and permanent magnets for magnetic refrigeration. AIP Advances 6.

Capovilla, M. S., Lozano, J. A., Trevizoli, P. V., Barbosa, Jr., J. R., 2016. Performance evaluation of a magnetic refrigeration system. Science and Technology for the Built Environment 22 (5), 534-543.

Cardoso, P. O., Destro, M. C., Alvarez, M. G., Lozano, J. A., Barbosa Jr., J. R., de Negri, V. J., 2016. Transient model and energy assessment of a digital solenoid valve system for a magnetic refrigerator. In: Proceedings of the 16th Brazilian Congress of Thermal Sciences and Engineering.

Dutra, S. L., Nakashima, A. T. D., Hoffmann, G., Lozano, J. A., Barbosa Jr., J. R., 2017. Using electrovalves as a flow distribution system for an active magnetic regenerator. In: Proceedings of thr 24th ABCM International Congress of Mechanical Engineering (COBEM 2017). Curitiba, Brazil.

Engelbrecht, K., 2008. A numerical model of an active magnetic regenerator refrigerator with experimental validation. PhD Thesis (Department of Mechanical Engineering), University of Wisconsin-Madison, USA. 
Engelbrecht, K., Eriksen, D., Bahl, C. R. H., Bjørk, R., Geyti, J., Lozano, J. A., Nielsen, K. K., Saxild, F., Smith, A., Pryds, N., 2012. Experimental results for a novel rotary active magnetic regenerator. International Journal of Refrigeration 35, 1498-1505.

Eriksen, D., April 2016. Active magnetic regenerator refrigeration with rotary multi-bed technology. PhD Thesis (Department of Energy Conversion and Storage), Technical University of Denmark, Denmark.

Eriksen, D., Engelbrecht, K., Bahl, C. R. H., 2015a. An active magnetic regenerator device. International Patent Application WO2015118007A1.

Eriksen, D., Engelbrecht, K., Bahl, C. R. H., Bjørk, R., 2016a. Exploring the efficiency potential for an active magnetic regenerator. Science and Technology for the Built Environment 22 (5), 527-533.

Eriksen, D., Engelbrecht, K., Bahl, C. R. H., Bjørk, R., Nielsen, K. K., 2016 b. Effects of flow balancing on active magnetic regenerator performance. Applied Thermal Engineering 103, 1-8.

Eriksen, D., Engelbrecht, K., Bahl, C. R. H., Bjørk, R., Nielsen, K. K., Insinga, A. R., Pryds, N., 2015b. Design and experimental tests of a rotary active magnetic regenerator prototype. International Journal of Refrigeration 58, $14-21$.

Hoffmann, G., Dutra, S. L., Cardoso, P. O., Nakashima, A. T. D., Lozano, J. A., Barbosa Jr., J. R., 2017. Actuation and control of electric valves for a magnetic refrigerator. In: Proceedings of thr 24th ABCM International Congress of Mechanical Engineering (COBEM 2017). Curitiba, Brazil.

Jacobs, S., Auringer, J., Boeder, A., Chell, J., Komorowski, L., Leonard, J., Russek, S., Zimm, C., 2014. The performance of a large-scale rotary magnetic refrigerator. International Journal of Refrigeration 37, 84-91.

Lozano, J. A., Capovilla, M. S., Trevizoli, P. V., Engelbrecht, K., Bahl, C. R. H., Barbosa Jr., J. R., 2016. Development of a novel rotary magnetic refrigerator. International Journal of Refrigeration 68, 187 - 197.

Lozano, J. A., Engelbrecht, K., Bahl, C. R. H., Nielsen, K. K., Eriksen, D., Olsen, U. L., Barbosa Jr., J., Smith, A., Prata, A. T., Pryds, N., 2013. Performance analysis of a rotary active magnetic refrigerator. Applied Energy $111,669-680$.

Nakashima, A. T., Dutra, S. L., Barbosa Jr., J. R., Trevizoli, P. V., 2017. Experimental evaluation of the flow inbalance in an active magnetic regenerator. In: Proceedings of the 9th World Conference on Experimental Heat Transfer, Fluid Mechanics and Thermodynamics. Iguazu Falls (Brazil). 
Plaznik, U., Tušek, J., Kitanovski, A., Poredoš, A., 2013. Numerical and experimental analyses of different magnetic thermodynamic cycles with an active magnetic regenerator. Applied Thermal Engineering 59, 52-59.

Teyber, R., Trevizoli, P. V., Niknia, I., Christiaanse, T. V., Govindappa, P., Rowe, A., 2017. Experimental performance investigation of an active magnetic regenerator subject to different fluid flow waveforms. International Journal of Refrigeration 74, 38-46.

Trevizoli, P. V., Christiaanse, T. V., Govindappa, P., Niknia, I., Teyber, R., Barbosa Jr., J. R., Rowe, A., 2016. Magnetic heat pumps: An overview of design principles and challenges. Science and Technology for the Built Environment $22(5), 507-519$.

Trevizoli, P. V., Nakashima, A. T., Peixer, G. F., Barbosa Jr., J. R., 2017. Performance assessment of different porous matrix geometries for active magnetic regenerators. Applied Energy 187, 847-861. 